University of Wollongong

Research Online

Australian Institute for Innovative Materials -

Papers

Australian Institute for Innovative Materials

2013

Porous titania nanosheet/nanoparticle hybrids as photoanodes for dyesensitized solar cells

\author{
Yang Bai \\ University of Queensland \\ Zheng Xing \\ University of Queensland \\ Hua Yu \\ University of Queensland \\ Zhen Li \\ University of Wollongong, zhenl@uow.edu.au \\ Rose Amal \\ University of New South Wales, r.amal@unsw.edu.au
}

See next page for additional authors

Follow this and additional works at: https://ro.uow.edu.au/aiimpapers

Part of the Engineering Commons, and the Physical Sciences and Mathematics Commons

Research Online is the open access institutional repository for the University of Wollongong. For further information contact the UOW Library: research-pubs@uow.edu.au 


\title{
Porous titania nanosheet/nanoparticle hybrids as photoanodes for dye- sensitized solar cells
}

\author{
Abstract \\ Porous titania nanohybrids (NHs) were successfully prepared by hybridizing the exfoliated titania \\ nanosheets with anatase $\mathrm{TiO} 2$ nanoparticles. Various characterizations revealed that the titania $\mathrm{NHs}$ as \\ photoanodes play a trifunctional role (light harvesting, dye adsorption, and electron transfer) in improving \\ the efficiency ( $\eta$ ) of the dye-sensitized solar cells. The optimized photoanode consisting layered NHs \\ demonstrated a high overall conversion efficiency of $10.1 \%$, remarkably enhanced by $29.5 \%$ compared to \\ that $(7.8 \%)$ obtained from the benchmark P25 nanoparticles under the same testing conditions.

\section{Keywords} \\ sensitized, solar, cells, nanosheet, nanoparticle, porous, hybrids, titania, photoanodes, dye

\section{Disciplines} \\ Engineering | Physical Sciences and Mathematics

\section{Publication Details} \\ Bai, Y., Xing, Z., Yu, H., Li, Z., Amal, R. \& Wang, L. (2013). Porous titania nanosheet/nanoparticle hybrids as \\ photoanodes for dye-sensitized solar cells. ACS Applied Materials and Interfaces, 5 (22), 12058-12065.

\section{Authors} \\ Yang Bai, Zheng Xing, Hua Yu, Zhen Li, Rose Amal, and Lianzhou Wang
}




\title{
Porous Titania Nanosheet/Nanoparticle Hybrids as Photoanodes for Dye-sensitized Solar Cells
}

\author{
Yang Bai, ${ }^{\dagger}$ Zheng Xing, ${ }^{\dagger}$ Hua Yu, ${ }^{\dagger}$ Zhen Li, $^{\ddagger}$ Rose Amal, ${ }^{\S}$ Lianzhou Wang* ${ }^{\dagger}$ \\ ${ }^{\dagger}$ ARC Centre of Excellence for Functional Nanomaterials, School of Chemical Engineering and Australian Institute for Bioengineering \\ and Nanotechnology, The University of Queensland, Brisbane, QLD 4072 Australia. \\ ${ }^{\ddagger}$ Institute of Superconducting and Elctronic Materials, Australian Institute of Innovative Materials, The University of Wollongong, \\ Northwollongong, NSW 2500, Australia. \\ ${ }^{\S}$ ARC Centre of Excellence for Functional Nanomaterials, School of Chemical Engineering, The University of New South Wales, Syd- \\ ney, NSW 2052, Australia.
}

ABSTRACT: Porous titania nanohybrids (NHs) were successfully prepared by hybridizing the exfoliated titanate nanosheets with the anatase $\mathrm{TiO}_{2}$ nanoparticles. Various characterizations revealed that the titania NHs as photoanodes play a tri-functional role (light harvesting, dye-adsorption and electron transfer) in improving the efficiency ( $\eta$ ) of the DSSCs. The optimized photoanode consisting layered $\mathrm{NHs}$ demonstrated a high overall conversion efficiency of $10.1 \%$, remarkably enhanced by $29.5 \%$ compared to that (7.8\%) obtained from the benchmark P25 nanoparticles under the same testing conditions.

KEYWORDS exfoliated titaniananosheets, anatasenanoparticles, hybrid photoanodes, dye-sensitized solar cells

\section{INTRODUCTION}

Inspired by the breakthrough work of M. Grätzel on dye-sensitized solar cells(DSSCS), ${ }^{1}$ much effort has been made on tailoring photoanode architectures to improve the overall conversion efficiency in the past decades ${ }^{2-7}$ One of major drawbacks of the conventional $\mathrm{TiO}_{2}$ nanoparticle photoanodes in DSSCs is the negligible light scattering of the films due to their small particle size ranging typically from ca $20-30 \mathrm{~nm}$, resulting in a low light harvesting efficiency. An optical scattering layer on top has been proposed as it could enhance the light harvest by localizing the incident light within the photoanode. So far, an array of light scattering materials has been investigated, including $\mathrm{TiO}_{2}$ mesoporous microspheres, ${ }^{7,8}$ hollow sphere ${ }^{9.11}$ and mirror-likenanoparticles ${ }^{12,13}$

Another major drawback of the conventional $\mathrm{TiO}_{2}$ nanoparticle photoanodes is the low transport efficiency of electrons, which imposesan upper limit on the film thickness. In afilm composed of $\mathrm{TiO}_{2}$ nanoparticles, electrons diffuse to the surface of collector electrode (e.g. FTO substrate) through azigzag pathway ${ }^{14}$ and may easily recombine with the oxidizing species (predominately triiodide ionsin the electrolyte), thus reducing the efficiency of DSSCs. Therefore, one-dimensional (1D) $\mathrm{TiO}_{2}{ }^{3,15-17}$ and $\mathrm{ZnO}$ nanostructures, ${ }^{5,14}, 18$ and two-dimensional (2D) nanosheet ${ }^{19,20}$ have attracted recent attention in facilitating electron transport in DSSCs.

Even though the light harvesting and charge transfer efficiency can beenhanced by introducing an optical light scattering layer and fabrication of films from 1D and 2D nanostructures respectively, the surface area that is accessible to the dye is usually sacrificed, resulting in insufficient dye adsorption and thus limited conversion efficiency. Thereby how to efficiently transfer electronsand harvest light without compromise in dye adsorption, is believed to be one of thekey challengesin achieving high-efficiency DSSCs.

Layered nanohybrids (NHs) by pillaring semiconducting nanoparticles such as $\mathrm{CdS}, \alpha-\mathrm{Fe}_{2} \mathrm{O}_{3}$, and $\mathrm{TiO}_{2}{ }^{21-24}$ into layered inorganic compound $s^{2530}$ have recently dramn growing attention in photoca talysis, due to their large surface areaaswell as suppressed electronhole recombination because of electron transfer between guest and host. ${ }^{22,} 23,31$ Titanate nanosheets $\left(\mathrm{Ti}_{0.91} \mathrm{O}_{2}\right)$ derived from delamina tion of layered compounds have unique structural characteristic of ultimate two-dimensional anisotropy with extremely small thicknessin the subnano- to nanometer scales, which leads to new physical and chemical properties for nanosheets ${ }^{32}$ In addition, the exfoliation of layered metal oxides into $2 \mathrm{D}$ nanosheets ${ }^{33}, 34\left(\mathrm{Ti}_{0.91} \mathrm{O}_{2}\right.$ nanosheets) makesit possible to pillar large-sized $\left(\mathrm{TiO}_{2}\right)$ nanoparticles into the interlayer space of host materials through an exfolia tion-restacking process of nanosheetsand guest particles ${ }^{23,35,36}$ The obtained pillared $\mathrm{NHs}$ possesses highly controllable physical and chemical properties ${ }^{22,37-39}$ In particular, due to the enlarged interlayer distance, the total surface areais significantly increased, facilitating chemical adsorption or reaction. Moreover, the energy band difference between guest and host will enhance the charge transfer between them. ${ }^{31},{ }^{40} \mathrm{Apart}$ from the high surface area and enhanced electron transfer efficiency, the large sized $2 \mathrm{D}$ nanosheets which constitute the layered NHs can act as an ideal optical scatter ${ }^{41}$ as well. In this regard, the layered titania NHs are expected to be promising photoanode candidates, playing a tri-functional role (light harvesting, dye-adsorption and electron transfer) for highefficiency DSSCs. 


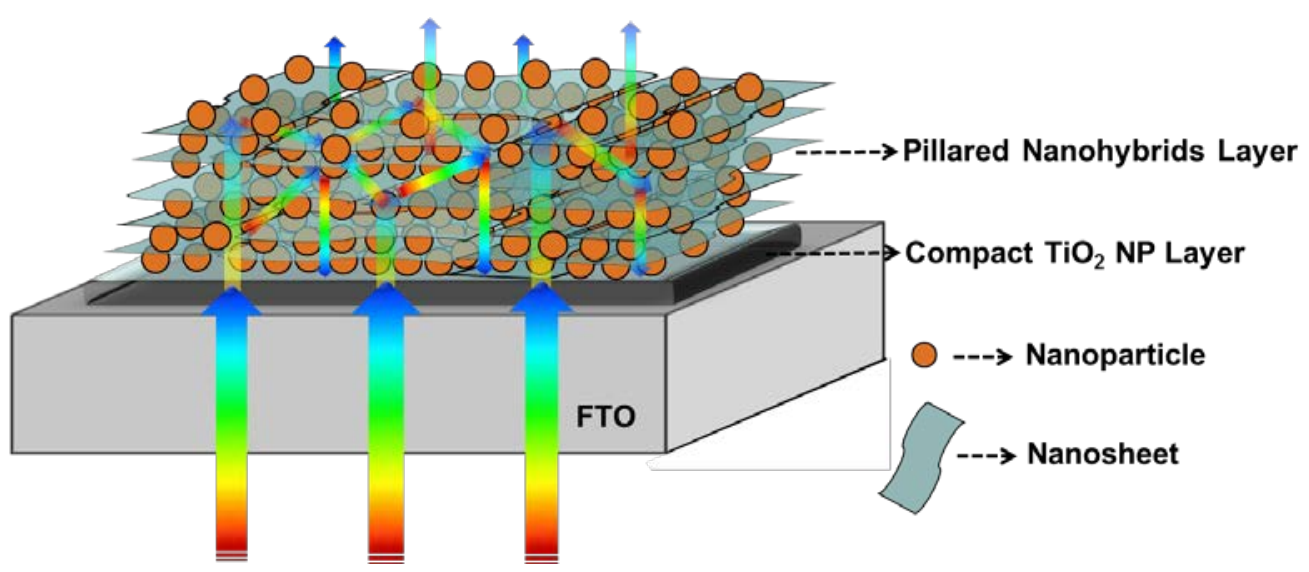

In this work, we report the layered $\mathrm{NHs}$ prepared by hybridizing the exfoliated titanate nanosheets $\left(\mathrm{Ti}_{0.91} \mathrm{O}_{2}\right)$ with the anatase $\mathrm{TiO}_{2}$ nanoparticles as shown in S-Figure. 1 for use as photoanodes in DSSCs. Our key strategy isto use exfoliation-reassembly strategy to introduce $\mathrm{TiO}_{2}$ nanoparticles ranging from 7 to $9 \mathrm{~nm}$ (SFigure. $2 b$ ) into the interlayers of $2 \mathrm{D}$ exfoliated $\mathrm{Ti}_{0.91} \mathrm{O}_{2}$ nanosheets ( $\mathrm{S}$ Figure. 2a) without deterioration of their fundamental crystal structures. In this way, the porosity and surface area of the NHs are expected to be significantly enlarged which is beneficial for sufficient dye-adsorption, and sub-micrometer sized nanosheets like the light shield will play a vital role in increasing the light scattering as shown in the idealized Scheme 1. In addition, we hypothesize the electron-hole recombination would be effectively suppressed due to the chargetransfer between the guest and host in the layered $\mathrm{NH}$ system. ${ }^{22,23,31}$ An enhanced overall conversion efficiency of $10.1 \%$ for layered titania nanosheet/ nanoparticle hybrid photoanode was achieved, a noticeable $29.5 \%$ improvement compared with the photoelectrode made of the benchmark Degussa $\mathrm{TiO}_{2} \mathrm{P}_{2} 5$ under the same testing conditions. Various characterizations confirmed our hypothesis and the feasibility of using new layered NH photoanodesfor efficiency improvement of DSSCs.

\section{EXPERIMENTAL SECTION}

Preparation of Titania Nanosheet/ Nanoparticle Nanohybrids Titaniananosheet $\left(\mathrm{Ti}_{0.91} \mathrm{O}_{2}\right)$ suspension was prepared according to Sasaki's method. 35, 36, 42, 43 Layered titanate precursor $\mathrm{Cs}_{0.68} \mathrm{Ti}_{1.83} \mathrm{O}_{4}$ was first prepared via a solid state reaction. In a typical synthesis, $\mathrm{Cs}_{2} \mathrm{CO}_{3}(7.694 \mathrm{~g})$ and $\mathrm{TiO}_{2}(10.0 \mathrm{~g})$ powders were ground for at least half an hour to obtain adequately mixture. The mixture was transferred to an alumina crucible and calcined at $760{ }^{\circ} \mathrm{C}$ for 30 minutes. The mixed powder was then reground for half an hour and re-calcined at $760{ }^{\circ} \mathrm{C}$ for 12 hours. The obtained $\mathrm{Cs}_{0.68} \mathrm{Ti}_{1.83} \mathrm{O}_{4}$ powder was subsequently proton-exchanged with excessamount of $\mathrm{HCl}(1 \mathrm{M})$ for 3 days, and the $\mathrm{HCl}$ solution was refreshed every 24 hours. The protonated titanate precursor $\mathrm{H}_{0.68} \mathrm{Ti}_{1.83} \mathrm{O}_{4} \bullet \mathrm{H}_{2} \mathrm{O}$ was dispersed in tetrabutylammonium hydroxide (TBAOH) solution containing the same amount of protons intercalated in the layered titanate. The white suspension wasthen shaken for over 1 week. To remove the un-exfoliated titanates, the suspension was centrifuged under $4700 \mathrm{rpm}$ for $5 \mathrm{~min}$ and the supernatant suspension was col- lected for use. Theobtained $\mathrm{Ti}_{0.91} \mathrm{O}_{2}$ Titaniananosheetssuspension hasaconcentration of around $1.79 \mathrm{~g} / \mathrm{L}$.

Anatase nanoparticleswere prepared viaahydrolysis method. In a typical preparation process, 1-propanol $(19.9 \mathrm{ml})$ and titanium isopropoxide (43.8ml) were first mixed. The mixed solution was then dropwiseadded to $300 \mathrm{ml}$ of diluted $\mathrm{HNO}_{3}$ solution ( $0.055 \mathrm{M}$ ) under vigorous stirring, and a white suspension can be observed. The white suspension was kept at $70-80{ }^{\circ} \mathrm{C}$ in water bath for 8 hours until opaque white suspension was obtained. Thereafter, the opaque white suspension was ultrasonicated by ultrasonication probe for 30 minutes. The anatase nanoparticles suspension had a concentration of $0.407 \mathrm{M}$. To prepare the anatase nanoparticle paste, diluted ammonia solution was added dropwise to the suspension under stirring until precipitates appeared. The top clear water was removed after standing for several hours and then the precipitateswere dried at $50^{\circ} \mathrm{C}$.

Titania NHs between nanosheets and anatase nanoparticles were synthesized as follows: under vigorous stirring, anatase nanoparticle suspension $(8.8 \mathrm{ml})$ was added to nanosheet suspension $(40 \mathrm{ml})$ dropwise. The suspension was then kept under $60^{\circ} \mathrm{C}$ overnight. To obtain the nanohybrids, the suspension was centrifuged and washed with distilled water and ethanol for several times.

Preparation of $\mathrm{TiO}_{2}$ Photoanodes To prepare the DSSC photoanodes, FTO substrates $(2.2 \mathrm{~mm}$ thickness, $8 \Omega / \mathrm{sq}$, Dyesol Glass) was cleaned with 2-propanol in an ultrasonic bath for 30 $\mathrm{min}$, followed by thoroughly rinsing with water. A compact layer (ca. $110 \mathrm{~nm}$ ) was firstly prepared by dip-coating $\mathrm{TiO}_{2}$ organic $\mathrm{sol}^{44}$ on the cleaned FTO surface, which not only have blocking effect but also can improve adherence between the $\mathrm{TiO}_{2}$ layer and FTO substrates. As described in our previous work ${ }^{45}, \mathrm{TiO}_{2}$ pastes of various samples including P25, anatase nanoparticle (NP) and layered titania nanohybrids ( $\mathrm{NHs}$ ) were prepared and then deposited on the FTO glass pre-treated with a $\mathrm{TiO}_{2}$ organic soll ${ }^{44}$ by the doctor-blade method ${ }^{45}$, and kept in a clean box for at least $15 \mathrm{~min}$ before heat treatment to reduce the surface irregularity and mechanical stress of the pastes. The working electrodes were put into a muffle furnace and heated at $450{ }^{\circ} \mathrm{C}$ for $30 \mathrm{~min}$. Finally, all the films were post-treated again with $\mathrm{TiO}_{2}$ organic sol.

Characterization of Layered NHs Powder and Films The crystalline phase and structure of the samples were determined by using a Bruker Advanced X-Ray Diffractometer (40 kV, $30 \mathrm{~mA}$ ) with $\mathrm{Cu} \mathrm{Ka} \alpha_{1}(\lambda=0.15406 \mathrm{~nm})$ radiation. The morphology of the 
layered NHs powder and films were examined by transmission electron microscopy (TEM, Tecnai Field Emission F20) and scanning electron microscopy (SEM, JEOL 6300). Brunauer-EmmettTeller (BET) surface areas ( $\mathrm{S}_{\mathrm{BET}}$ ) were analyzed with nitrogen

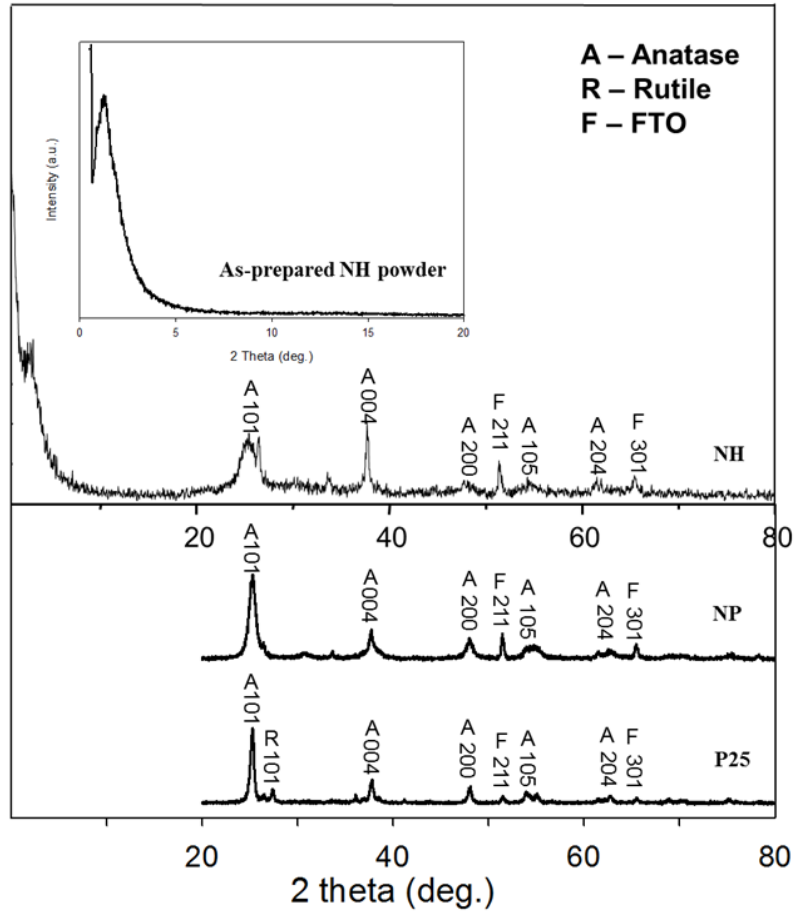

Figure 1. XRD patterns of $\mathrm{P} 25, \mathrm{TiO}_{2}$ nanoparticle (NP), layered titania nanohybrid $(\mathrm{NH})$ films on $\mathrm{FTO}$ substrates and asprepared layered titania NHspowder.

adsorption apparatus (Quadrasorb $\mathrm{S}$ ). The film powder was obtained by scratching calcined films off FTO glass and all samples were degassed at $200{ }^{\circ} \mathrm{C}$ overnight before the measurement. The dye desorption was performed by immersing the dye-sensitized films in a $0.1 \mathrm{M}$ of $\mathrm{NaOH}$ in ethanol-water ( $\mathrm{v} / \mathrm{v}=1: 1)$ solution?. The dye-uptake capacity of each photoanode was determined from the absorption value for each $\mathrm{NaOH}$ / dye solution by UV-vis spectrophotometer (Shimadzu UV-2450). The scattering and absorption properties of all samples were investigated with UV-visible diffused reflectancel light absorption spectrometer (Shimadzu UV2450).

Fabrication and Measurements of DSSCS Dye-loading was performed by immersing the working electrodes into a $0.5 \mathrm{mM}$ N719 (Dyesol) dye solution in a 1:1 (v/ v) mixture of acetonitrile and tert-butanol, and kept for 12-14 hours. Counter electrodes were fabricated by spin-coating $\mathrm{H}_{2} \mathrm{PtCl}_{6}$ isopropanol solution $(5 \mathrm{mM})$ on FTO substrates and heating at $380{ }^{\circ} \mathrm{C}$ for $15 \mathrm{~min} .{ }^{44}$ Then the dye-sensitized working electrode and Pt-counter electrode were assembled into a sandwich-type cell as described in our previouswork. ${ }^{46}$

The photocurrent density-voltage $(J-V)$ curves were recorded by using an Orie AM 1.5 solar simulator equipped with an AM 1.5G type filter (Newport, 81094) and a Keithley model 2420 digital source meter. The dark current scan was performed in the similar condition but without illumination. IPCE plotted as a function of excitation wavelength was obtained by using a Nemport 1918-c power meter under the irradiation of a $300 \mathrm{~W}$ Oriel xenon light source with an Oriel Cornerstone 260 1/ 4 m monochromator in DC mode. ${ }^{14}$ The open-circuit voltage decay (OCVD) was carried out by switching off theillumination on DSSC on asteady stateand

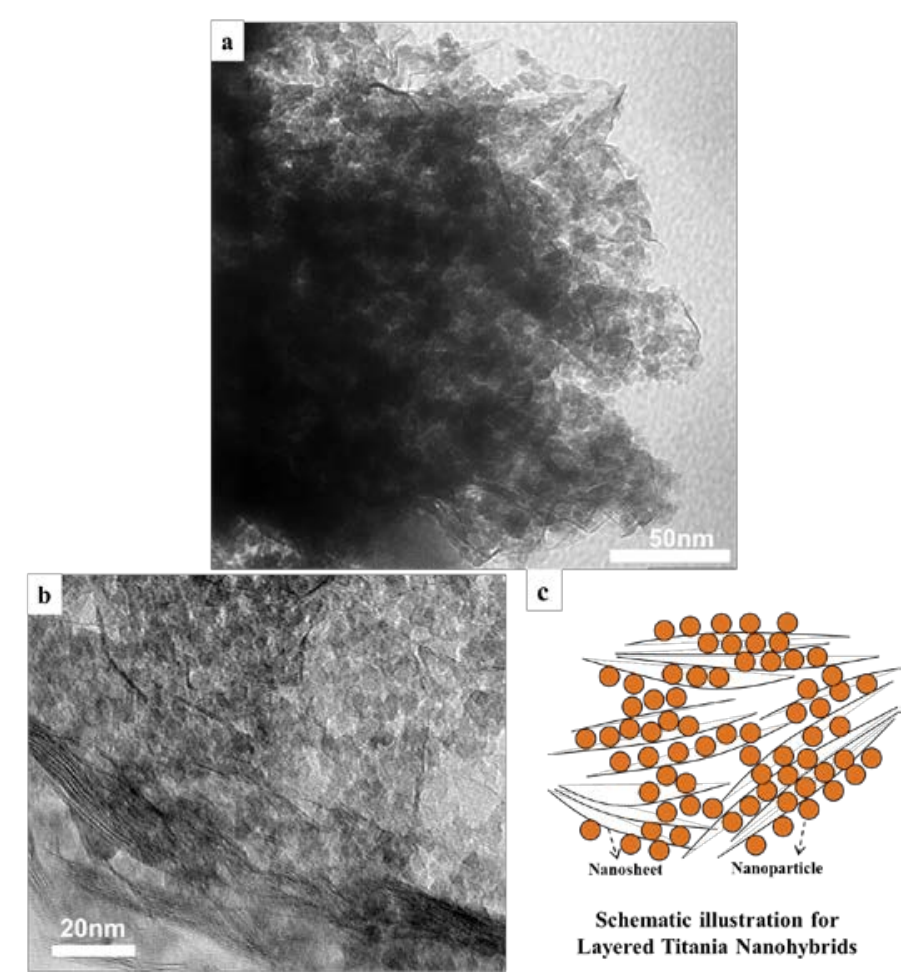

Figure 2. (a) Typical TEM image of the restacked NH sample; (b) highmagnification TEM image showing the lamellar structure; (c) schematic illustration of layered titaniaNHs.

monitoring the decay of the open-circuit voltage $\left(V_{o c}\right){ }^{20}$ Electrochemical impedance spectroscopy (EIS) was mearsured by the Solartron 1480 Potentiostat in a frequency range of $10^{6}-0.1 \mathrm{~Hz}$ under dark and the applied bias voltage and ac amplitude were set as $-0.7 \mathrm{~V}$ and $10 \mathrm{mV}^{14}$

\section{RESULTSAND DISCUSSON}

\section{Characterization of Layered $\mathrm{NH}$ powder and VariousFilms}

The resultant layered NH powder and various films were comprehensively characterized and Figure 1 shows XRD patterns of theas prepared $\mathrm{NH}$ powder and films prepared with $\mathrm{P} 25$, sol-gel derived $\mathrm{TiO}_{2}$ nanoparticles (NP) and NH samples printed on FTO substrates. As indicated in the XRD patterns, both the NP and NH samples are pure anatase (A) phase (JCPDS No. 21-1272) with typical peaks (101), (004) and (200), whereas all diffraction peaks of the P25 films can be well indexed to a mixture of anatase (A) $\mathrm{TiO}_{2}$, and rutile (R) $\mathrm{TiO}_{2}$ (JCPDSNo. 21-1276). Peaks F belong to FTO substrates The Raman spectrum of NH film further confirmed the anatase phase with typical vibrational bands as marked on SFigure 4. The inset shows a poorly-resolved 001 indice $(2 \theta=$ $1.24^{\circ}$ ) for the as-prepared $\mathrm{NH}$, which can be attributed to the formation of disordered porous titania heterostructure consisting of nanosheets and nanoparticles in some domains. An electrostatic interaction between negatively charged titanate nanosheets and positively charged $\mathrm{TiO}_{2}$ nanoparticles is believed to be a driving force for the formation of such type disordered heterostructure. ${ }^{22}$ The discernible broad 001 reflection for the $\mathrm{NH}$ film after heat treatment shifted toward the higher angle side $\left(2 \theta=2.46^{\circ}\right)$, indicative of the shrinkage in basal spacing mainly attributed to the dehydroxylation of $\mathrm{TiO}_{2}$ nanosol particles but maintenance of the $\mathrm{NH}$ structure. 

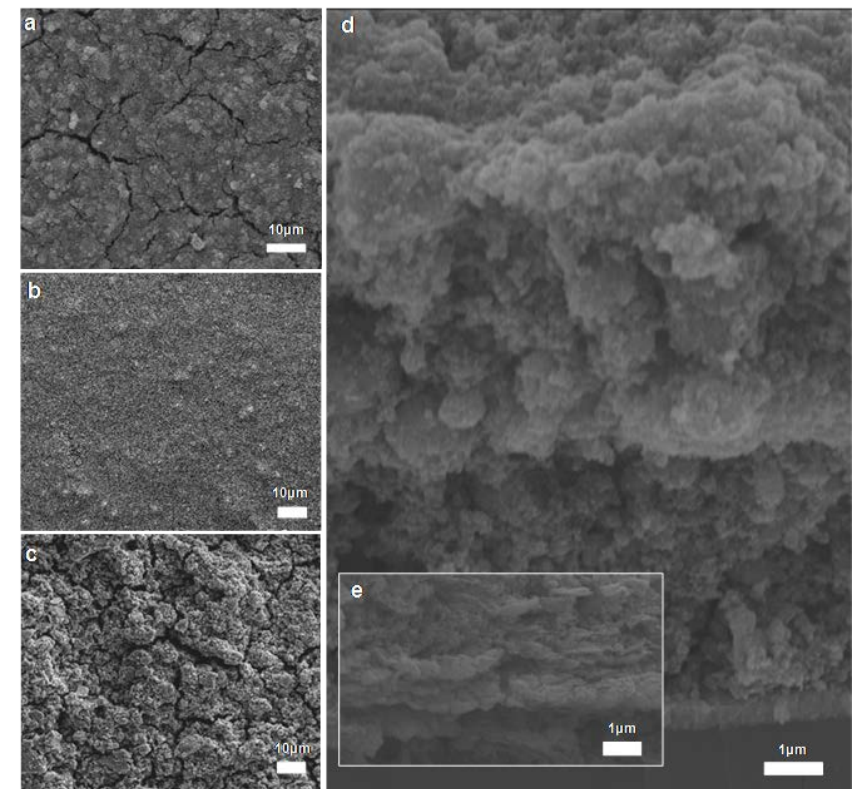

Figure 3. Surface SEM images of a) layered NH, b) P25 and c) nanoparticle films, d) cross-sectional SEM images of a whole layered NH film; e) high-magnification cross-sectiona SEM images of randomly selected areain the layered $\mathrm{NH}$ film showing the layered structure.

The formation of the layered NH structure was further confirmed using TEM analysis. Figure 2a and SFigure 3 depict the typical TEM image of restacked NHs. High-resolution TEM image in Figure $2 \mathrm{~b}$ exhibits an assembly of parallel dark lines $\left(\mathrm{Ti}_{0.91} \mathrm{O}_{2}\right.$ nanosheets) and spherical shapes $\left(\mathrm{TiO}_{2}\right.$ nanoparticles) in some domains. Unlike highly ordered pillared structure prepared from the restacking of exfoliated nanosheets with small-sized guest species such as $\mathrm{Li}^{+}, \mathrm{Al}_{13}{ }^{+}$clusters, ${ }^{47,48}$ it's understandable that restacking of larger $\mathrm{TiO}_{2}$ nanoparticles with extremely thin nanosheets is much more difficult to control, thus leading to poorly-ordered layered structure. As shown in Figure $2 \mathrm{a}$ and $\mathrm{b}$, the exfoliated $\mathrm{Ti}_{0.91} \mathrm{O}_{2}$ nanosheets are randomly hybridized with $\mathrm{TiO}_{2}$ nanoparticles, which is in good agreement with the XRD results. Figure $2 \mathrm{c}$ is the idealized schematic illustration of the highly disordered $\mathrm{NH}$ structure for better understanding.

In order to further verify the disordered layered structure in the calcined films, SEM characterization was carried out to observe the resultant structures. The plate-like surface of $\mathrm{NH}$ film (Figure 3a) is quite different from that of P25 and NP films (Figure 3b, c). Although somemicro-crackscan be found in SEM images, to some extent this can be optimized by a following post-treatment step with $\mathrm{TiO}_{2}$ sol. The optical property (will be discussed later) also confirm that the light harvesting of the filmswasnot affected much by such micro-cracks. As shown in the crosssectional image (Figure 3d), all the films have a thickness of ca12.3 $\mu \mathrm{m}$. High magnification cross-sectional images were taken randomly through the whole cross-section of the NH films. Upon heat treatment, disordered micron thick layer will be formed, consisting of several layers of nanosheets and nanoparticles. As shown in Figure 3e, the micron thick layered structure can be clearly visualized within the $\mathrm{NH}$ film after calcination.

The nitrogen adsorption-desorption isotherms of as-prepared $\mathrm{NH}$ powder and film powder scratched off from the calcined $\mathrm{NH}$ films shown in Figure 4 provide further evidence for the

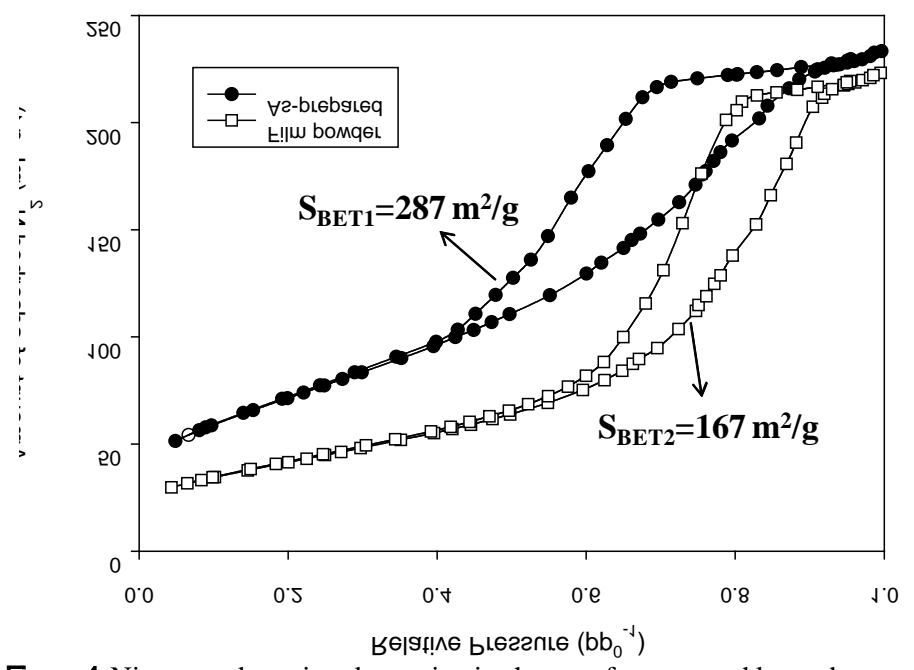

Figure4. Nitrogen adsorption-desorption isotherms of as-prepared layered NHs powder and powder scratched off from the calcined NH films.

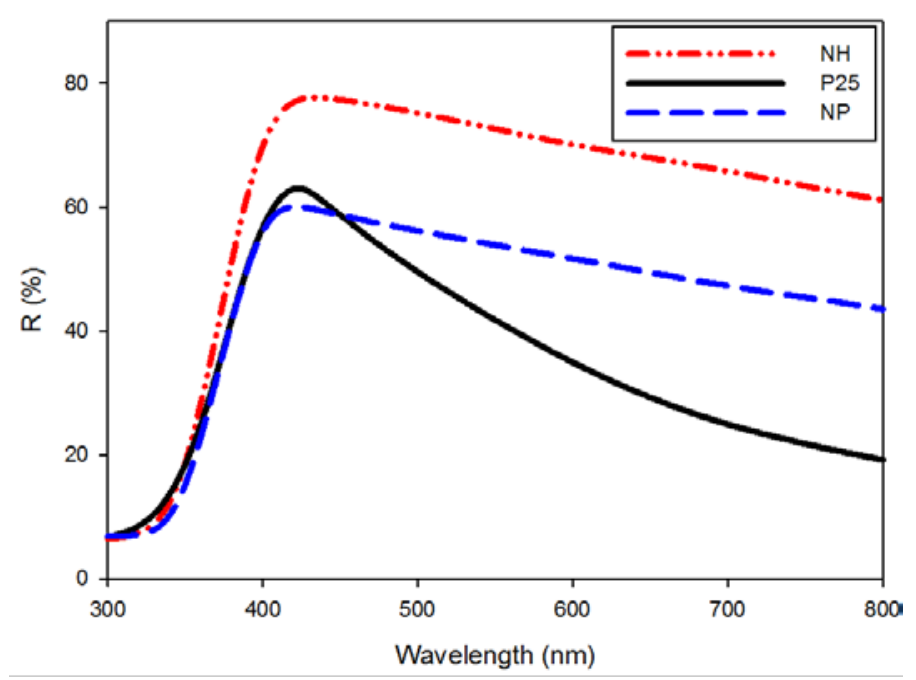

Figure5. Diffused reflectance spectra of the P25, NP and layered NH films.

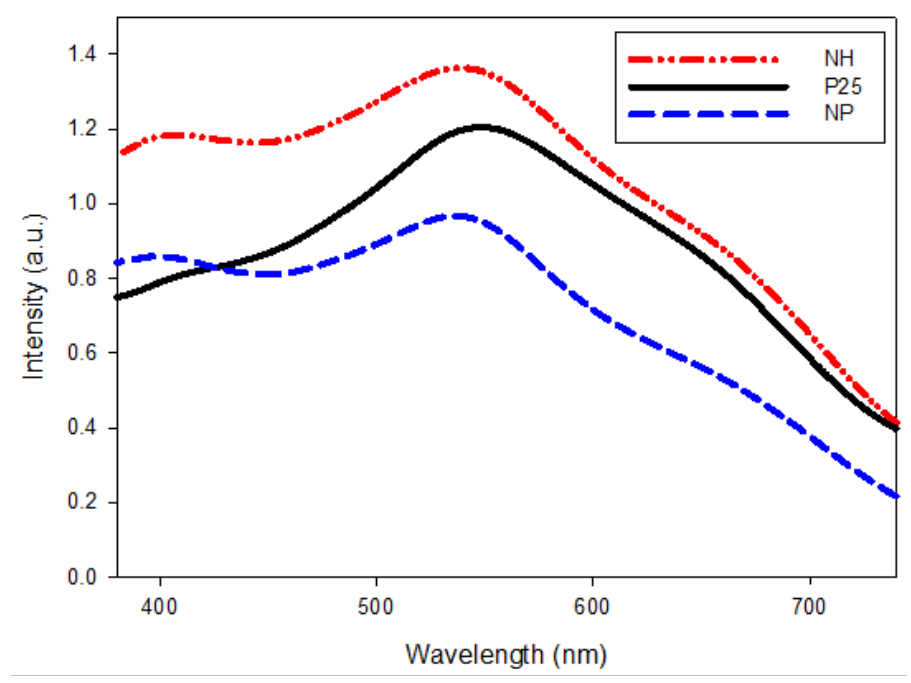

Figure6. UV-vis absorption spectra of the P25, NP and layered NH films with dye adsorbed.

\section{4}



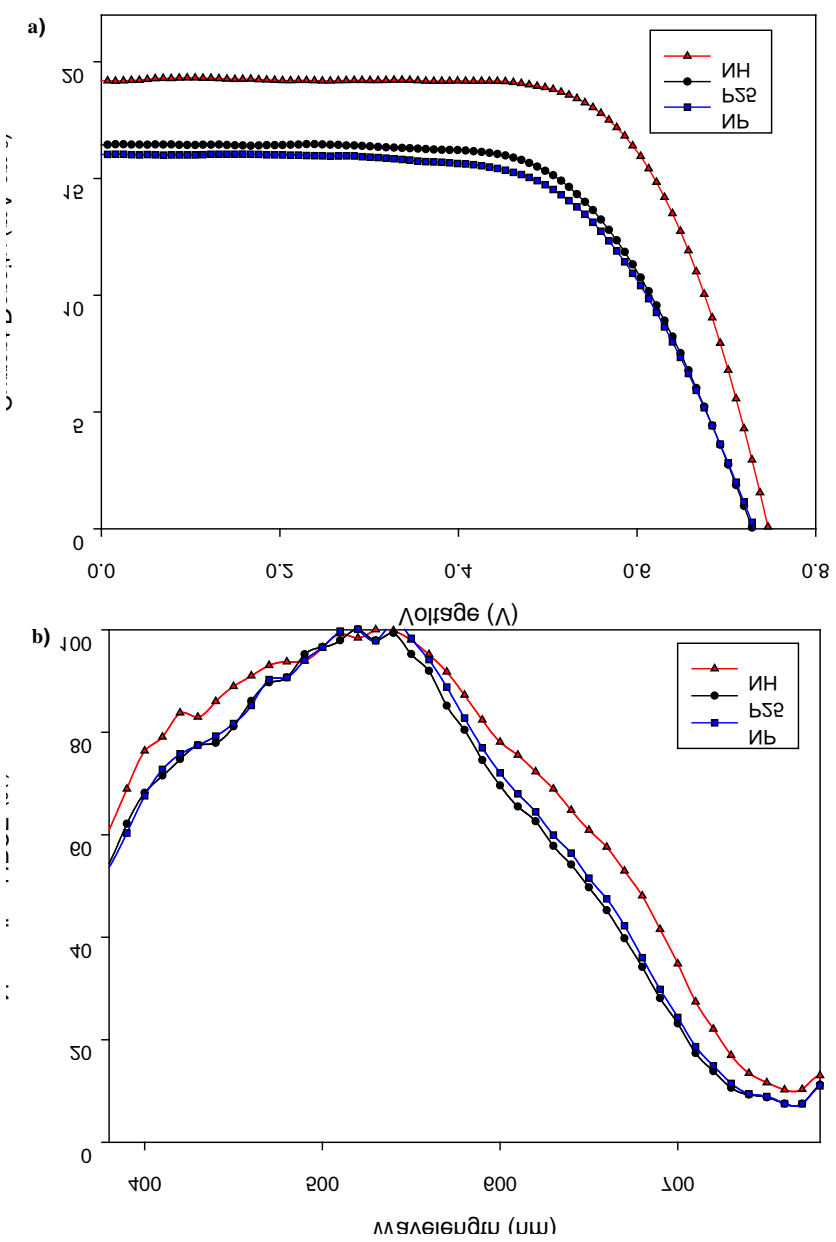

Figure 7. a) $\mathcal{H} V$ curves and b) Normalized IPCE of DSSCs based on P25, NPand layered $\mathrm{NH}$ photoanodes.

formation of porous layered structure by reassembling exfoliated $\mathrm{Ti}_{0.91} \mathrm{O}_{2}$ nanosheets in the presence of anatase nanoparticles. The $\mathrm{NHs}$ shows a type IV isotherm, characteristics of mesoporous structurein the materials. Thisclearly reveals that themesoporesin the $\mathrm{NHs}$ were developed by random hybridization of $\mathrm{Ti}_{0.91} \mathrm{O}_{2}$ nanosheets with anatase nanoparticles. In addition, the mesoporous $\mathrm{NH}$ s show the type $\mathrm{H} 3$ hysteresis loop in the IUPAC classification, suggesting that the dit-shaped poreswereformed. Asshown in Figure 4, the Brunauer-Emmett-Teller (BET) specific surface area of the as-prepared sampleswas quite high ( $287 \mathrm{~m}^{2} / \mathrm{g}$ ), the film powder decreased to $167 \mathrm{~m}^{2} / \mathrm{g}$ as a result of heat treatment at 450 ${ }^{\circ} \mathrm{C}$.

\section{Diffused Reflectivity and UV-visAbsorption}

The reflectivity of each film was studied to investigate the scattering effect of the layered NHs. Figure 5 shows the diffused reflectance spectra of various samples. Apparently, layered NH films had much higher reflectivity in the wavelength range of $380-800 \mathrm{~nm}$ than that of NP and P25 films. This evidence confirms our hypothesis on the efficient light scattering of layered NHs acting as light shields. Note that the reflectivity of NP film is sightly higher than that of P25 film in the same wavelength range, possibly due to the aggregation of sol-gel prepared nanoparticles(Figure 3c). In order to study the photovoltaic properties of DSSCsbased on thelayered $\mathrm{NHs}$, dye loading was first investigated (Table 1). Prior to dye loading measurement, UV-visabsorption
Table 1. Comparison of Photovoltaic Properties, BET Surface Areaand Dyeloading of P25, NP and Layered NH Photoanodes

\begin{tabular}{ccccccc}
\hline Samples & $\begin{array}{c}J_{s c} \\
{\left[\mathrm{~mA}_{\mathrm{cm}}{ }^{2}\right]}\end{array}$ & $\begin{array}{c}V_{o c} \\
{[\mathrm{~V}]}\end{array}$ & $\begin{array}{c}F F \\
{[\%]}\end{array}$ & $\begin{array}{c}\eta \\
{[\%]}\end{array}$ & $\begin{array}{c}\text { S } \\
\text { Value } \\
{\left[\mathrm{m}^{2} / \mathrm{g}\right]}\end{array}$ & $\begin{array}{c}\text { Dye-loading } \\
{\left[10^{-7} \mathrm{~mol} / \mathrm{cm}^{2}\right]}\end{array}$ \\
\hline P25 & 16.4 & 0.73 & 65 & 7.8 & 51 & 1.80 \\
$\mathrm{NP}$ & 15.9 & 0.73 & 64 & 7.4 & 43 & 1.65 \\
$\mathrm{NH}$ & 19.2 & 0.75 & 70 & 10.1 & 167 & 2.05 \\
\hline
\end{tabular}

${ }^{a}$ Measurements were performed under AM 1.5G one sun (light intensity: 100 $\mathrm{mWcm}{ }^{-2}$ ), the active areas were ca. $0.16 \mathrm{~cm}^{2}$ for all of the cells and the average value of each data was obtained by testing $6 \sim 8$ cells.

${ }^{\mathrm{b}}$ Dye-absorbed films with a dimension of $c a 3 \mathrm{~cm}^{2}$ were used for estimating the dye uptake.

was carried out for all three different films with dye adsorbed as shown in Figure 6. Compared with the $\mathrm{TiO}_{2}$ nanoparticle films ( NP and P25), the layered NH films showed a higher absorption in the wavelength range from $400 \mathrm{~nm}$ to $700 \mathrm{~nm}$, which is consistent with the significantly increased dye-loading indicated in Table 1 and corresponding photos as shown in S-Figure 5. In addition, we found that as monolayer adsorption ${ }^{49,50}$ the dye-loading amount is quite comparable with those reported in other literatures. ${ }^{7,9,17}$ This higher dye-loading can be attributed to the large surface area of the layered NH films, as verified by BET specific surface area $\left(\mathrm{S}_{\mathrm{BET}}\right)$ measurements (Table 1).

\section{Photocurrent Density-Voltage(JV) Characteristics}

The photovoltaic performance of layered $\mathrm{NH}$ photoelectrode were analyzed against the photoelectrodes fabricated with P25 and NP as listed in Table 1, with the short current density-voltage $(\mathcal{H}$ ) characteristics of DSSCs shown in Figure 7a. Table 1 compares the photovoltaic properties of DSSCs based on various films with a thickness of ca $12.3 \mu \mathrm{m}$. Due to insufficient light harvesting and inefficient electron transfer, DSSCs assembled with P25 showed a limited efficiency of 7.8\% (comparable with the efficiency reported in literature $\mathrm{e}^{9,12,51}$ as well as that of devices made from Dyesol paste shown in S-Figure 7), with relatively small $\mathcal{J}_{c}\left(16.4 \mathrm{mAcm}^{-2}\right)$, opencircuit voltage ( $V_{o c}, 0.73 \mathrm{~V}$ ) and fill factor (FF, 65\%). Whereas all the key parameters of DSSCs based on layered NHs were improved ( J J $_{0}: 19.2 \mathrm{~mA} \mathrm{~cm}^{-2}$; Voc: $0.75 \mathrm{~V}$; FF. 70\%), which resulted in enhanced overall conversion efficiency $(\eta)$ of $10.1 \%$ (close to the champion efficiency of $12.3 \% \%^{52}$ ). The possible explanation for the higher $V_{o c}$ of the hybrid cells is the blocking of recombination as a result of charge transfer ${ }^{22,23,30,31,53,54}$ within the layered $\mathrm{NH}$ film, which results in an increase in electron density in $\mathrm{TiO}_{2}$, and thus the shift of Fermi level. ${ }^{55}$ As evidenced above, the large surface area makes it accessible for more dye-adsorption, and the light scattering effect of the re-assembled exfoliated titanates favour enhanced light-harvesting efficiency by increasing the optical length serving as light-scattering shield, and thereby enhanced $b_{c}$ for the cell with the layered $\mathrm{NH}$ film., ${ }^{56}$ The faster electron diffusion rate $\mathrm{e}^{57,58}$ in the $\mathrm{NH}$ film can be considered as the reason for the higher $F F$ of the cell assembled with NH films, as compared with the cell using P25 film.

Note that the DSSC made of anatase nanoparticle (NP) film showed a slightly decreased $J_{c}$ and $\eta$. This could be mainly caused by the lower dye loading in this NP film due to the decreased surface area as a result of aggregation. Whereas in the case of layered $\mathrm{NH}$ sample, the randomly hybridized layered $\mathrm{Ti}_{0.91} \mathrm{O}_{2}$ inhibit 5 $\mathrm{TiO}_{2}$ nanoparticle growth upon calcination. 

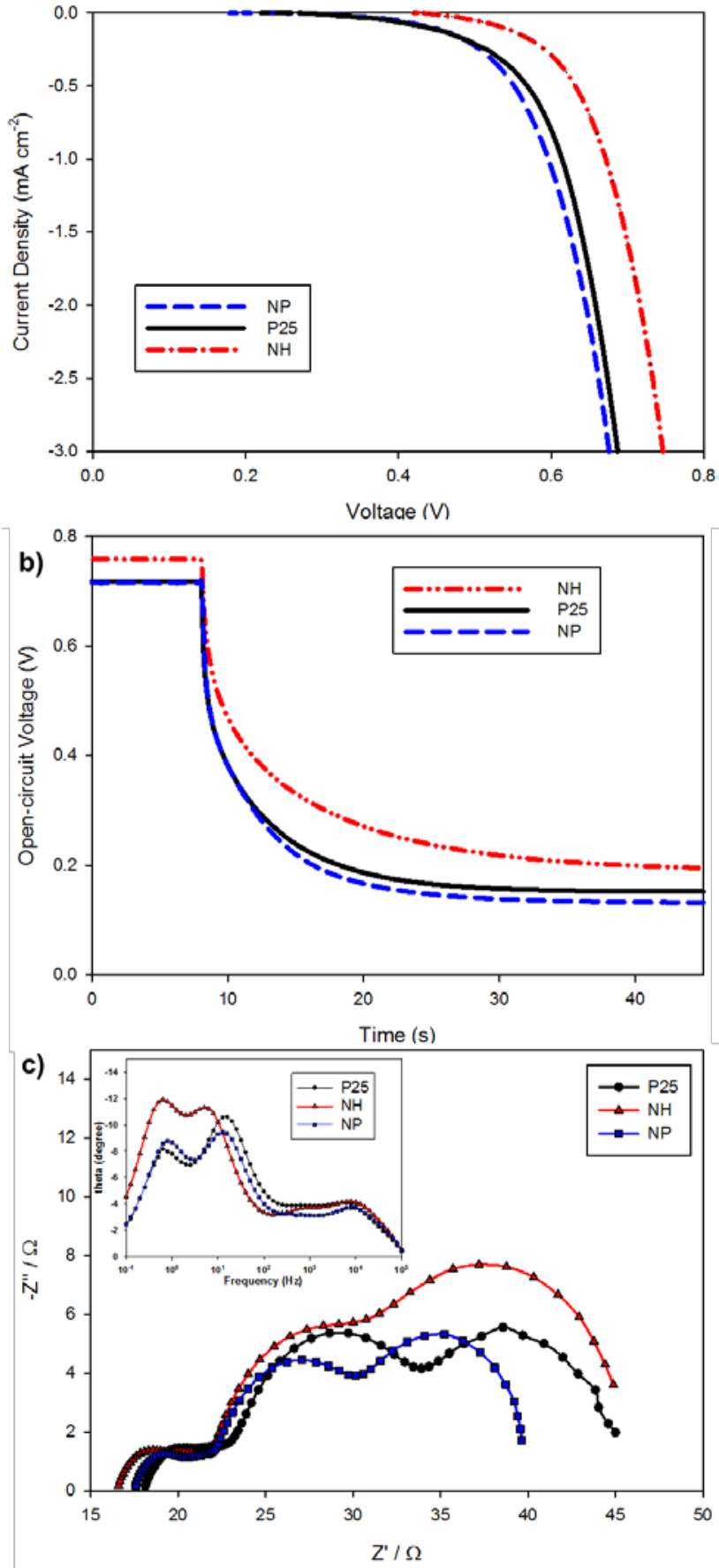

Figure 8. a) Dark current potential scans, b) Open-circuit voltage decay profilesand c) impedance spectra of DSSCs based on P25, NP and layered $\mathrm{NH}$ photoanodes TheBode phase plot is shown in theinset of (c).

\section{Incident Photon-to-Current Conversion Efficiency (IPCE) Per-} formance

The IPCE spectra of the various photoanodes as a function of the illumination wavelength can provide further evidence on the scattering effect of the NH structure. The IPCE of the NH film based DSSCs(SFigure6) showed aconsiderableincrease over the entire wavelength range. To better determine the superior optical characteristic of the titania nanohybrids, the normalized IPCE was obtained by normalizing the measured IPCE to the maximum intensity of $520 \mathrm{~nm}$, as shown in Figure $7 \mathrm{~b}$. We can then clearly visualize the impact of this new NH structure on the light conversion efficiency of the lower energy photons in the long wavelength range, from $560 \mathrm{~nm}$ until far in the absorption tail (up to $750 \mathrm{~nm}$ ). The full spectrum enhancement of $\mathrm{NH}$ devices compared with that of P25 and NP should be evidently attributed to the increased dye adsorption (large surface area) and efficient light scattering (nanosheetscomponent).

\section{DarkCurrent, OCVD and $\boxminus S$}

To further investigate the origin and evidence for the enhanced efficiency especially the improved $V_{o c}$ and FF of the layered $\mathrm{NH}$ based cells, the dark current potential scans were performed as shown in Figure 8a, which was employed to estimate the charge carrier recombination in DSSCs. It is generally believed that electron recombination is attributed to the reduction of $I_{3}{ }^{-}$ions by electrons on the FTO substrate, which will result in a decrease in photocurrent. ${ }^{59}$ Compared with the NP and P25 film, the onset of dark current for DSSCs with the layered NH film occurred at a higher potential and a smaller dark current was produced under the same bias above $0.4 \mathrm{~V}$. This result indicates a sower recombination rate between the transferred electrons and $\mathrm{I}_{3}{ }^{-}$ions for the $\mathrm{NH}$ film. ${ }^{60,61}$ Since the suppression of back electron transfer in the layered $\mathrm{NHs}$, the increased $V_{o c}$ and $F F$ were achieved and consequently improved overall conversion efficiency.

The open-circuit voltage decay (OCVD) technique was employed to further examine the charge transfer kinetics of the DSSCs. Before the measurement, a steady-state voltage for the DSSC cell was obtained under illumination and the subsequent decay of $V_{o c}$ wasthen recorded after theillumination wasinterrupted. The decay of the $V_{o c}$ can beviewed as asign of electron lossasa result of the electron-hole recombination. 20, ${ }^{62}$ As shown in Figure $8 b$, the decay rate of $V_{o c}$ is apparently sower in DSSCs assembled with the layered $\mathrm{NHs}$, implying a reduced charge recombination rate in comparison with that of DSSCs fabricated by anatase NP and P25, which isin good agreement with the result in Figure 8a

To better elucidate the electron transport and charge recombination in $\mathrm{NH}$ photoelectrodes, electrochemical impedance spectroscopy (EIS) was performed in the dark under aforward bias of $0.7 \mathrm{~V}$ as shown in Figure 8c and the inset shows the Bode phase plot. As observed in the Nyquist plots, the radius of the middle semicircle increase in the order $\mathrm{NP}<\mathrm{P} 25<\mathrm{NH}$, implying a larger electron recombination resistance for $\mathrm{NH}$ electrodes ${ }^{63}$ In addition, the middle-frequency peak of DSSCs based on $\mathrm{NH}$ electrodes shown in the Bode phase plots shifts to lower frequency relative to P25 and NP, which indicates that the electron lifetime was prolonged in $\mathrm{NH}$ based DSSCs ${ }^{64}$ Therefore, the larger electron re combination resistance and longer electron lifetime observed in $\mathrm{NH}$ relative to P25 and NP based DSSCs illustrate more effective suppression of the back reaction of theinjected electron with the $I_{3}{ }^{-}$ in the electrolyte due to the electron transfer between guest and host ${ }^{22,}, 23,31$ and better explained the observed improvements in both the photocurrent and photovoltage, yielding substantially enhanced energy conversion efficiency. ${ }^{63}$

\section{CONCLUSONS}

In summary, a new type of porous layered titania NHs were succesfully prepared by hybridizing the exfoliated titanate with the anatase $\mathrm{TiO}_{2}$ nanosol, which was subsequently used as a trifunctional photoanode for high efficiency DSSCs. Reflectance spectra demonstrate that the light-harvesting efficiency of the $\mathrm{NH}$ filmswas significantly higher than that of P25 film due to the effectivelight-scattering of $\mathrm{Ti}_{0.91} \mathrm{O}_{2}$ nanosheets. The larger surface area of the layered $\mathrm{NH}$ films leading to increased dye-loading is veri-6 
fied by BET specific surface area measurements. In addition, not only the dark current potential scan but also the open circuit voltage decay indicates a lower charge recombination for photoelectrode fabricated with NHs. The DSSCs assembled using photoanode with layered NHs demonstrated a high overall conversion efficiency of $10.1 \%$, remarkably enhanced by $29.5 \%$ compared to that (7.8\%) obtained from the benchmark P25 nanoparticles. Layered NHs may lead to a new way in the fine-tuning of photoanode structures for high efficiency DSSCs as well as boosting the efficiency of Quantum dot-sensitized solar cells.

\section{ASSOCIATED CONTENT}

Supplementary figures. This material is available free of charge via the Internet at http:// pubs.acs.org.

\section{AUTHOR INFORMATION}

\section{Corresponding Author}

*Email: l.wang@uq.edu.au

Notes

The authors declare no competing financial interest.

\section{ACKNOWLEDGMENT}

This work was financially supported by the Australian Research Council (ARC) through Discovery Projects. YB acknowledges the support from Chinese Scholarship Council (CSC).

\section{REFERENCES}

1. O'Regan, B.; Gratzel, M., Nature 1991, 353, 6346, 737740.

2. Ko, S. H.; Lee, D.; Kang, H. W.; Nam, K. H.; Yeo, J. Y.; Hong, S. J.; Grigoropoulos, C. P.; Sung, H. J., Nano Lett. 2011, 11, 2,666-671.

3. Liu, B.; Aydil, E. S., J. Am. Chem. Soc. 2009, 131, 11 , 3985-3990.

4. Zhang, Q. F.; Chou, T. P.; Russo, B.; Jenekhe, S. A.; Cao, G. Z., Angew. Chem. Int. Ed. 2008, 47, 2402-6.

5. Law, M.; Greene, L. E.; Johnson, J. C.; Saykally, R.; Yang, P., Nat. Mater. 2005, 4, 6, 455-459.

6. Zhu, K.; Neale, N. R.; Miedaner, A.; Frank, A. J., Nano Lett. 2007, 7, 1, 69-74.

7. Huang, F. Z.; Chen, D. H.; Zhang, X. L.; Caruso, R. A.; Cheng, Y. B., Adv. Funct. Mater. 2010, 20, 8, 1301-1305.

8. $\quad$ Yan, K. Y.; Qiu, Y. C.; Chen, W.; Zhang, M.; Yang, S. H., Energy Environ. Sci. 2011, 4, 6, 2168-2176.

9. Wu, X.; Lu, G. Q.; Wang, L., Energy Environ. Sci. 2011, 4, 9, 3565-3572.

10. Koo, H. J.; Kim, Y. J.; Le, Y. H.; Le, W. I.; Kim, K.; Park, N. G., Adv. Mater. 2008, 20, 1, 195-199.

11. Qian, J. F.; Liu, P.; Xiao, Y.; Jang, Y.; Cao, Y. L.; Ai, X. P.; Yang, H. X., Adv. Mater. 2009, 21, 36, 3663-3667.

12. $Y u, H$.; Ba, Y.; Zong, X.; Tang, F. Q.; Lu, G. Q. M.; Wang, L. Z., Chem. Commun. 2012, 48, 59, 7386-7388.

13. Zhang, H. M.; Han, Y. H.; Liu, X. L.; Liu, P.; Yu, H.; Zhang, S. Q.; Yao, X. D.; Zhao, H. J., Chem. Commun. 2010, 46, 44, 8395-8397.

14. Bai, Y.; Yu, H.; Li, Z.; Amal, R.; Lu, G. Q.; Wang, L. Z., Adv. Mater. 2012, 24, 43, 5850-5856.

15. Ohsaki, Y.; Masaki, N.; Kitamura, T.; Wada, Y.; Okamoto, T.; Sekino, T.; Niihara, K.; Yanagida, S, Phys Chem. Chem. Phys. 2005, 7, 24, 4157-4163.
16. Zhu, K.; Vinzant, T. B.; Neale, N. R.; Frank, A. J., Nano Lett. 2007, 7, 12, 3739-3746.

17. Adachi, M.; Murata, Y.; Takao, J.; Ju, J. T.; Sakamoto, M.; Wang, F. M., J Am. Chem. Soc. 2004, 126, 45, 14943-14949.

18. Xu, F.; Sun, L., Energy Environ. Sci. 2011, 4, 3, 818-841.

19. Lin, C. Y.; Lai, Y. H.; Chen, H. W.; Chen, J. G.; Kung, C. W.; Vittal, R.; Ho, K. C., Energy Environ. Sci. 2011, 4, 9, 34483455.

20. Wu, X.; Chen, Z. G.; Lu, G. Q.; Wang, L. Z., Adv. Funct. Mater. 2011, 21, 21, 4167-4172.

21. Fujishiro, Y.; Uchida, S; Sato, T., Int. J. Inorg. Mater. 1999, 1, 1, 67-72.

22. Kim, T. W.; Hur, S. G.; Hwang, S. J.; Park, H.; Choi, W.; Choy, J. H., Adv. Funct. Mater. 2007, 17, 2, 307-314.

23. Choy, J. H.; Lee, H. C.; Jung, H.; Kim, H.; Boo, H., Chem. Mater. 2002, 14, 6, 2486-2491.

24. Geng, F.; Ma, R.; Nakamura, A.; Akatsuka, K.; Ebina, Y.; Yamauchi, Y.; Miyamoto, N.; Tateyama, Y.; Sasaki, T., Nat Commun2013, 4, 1632.

25. Paek, S-M.; Jung, H.; Park, M.; Lee, J.-K.; Choy, J.-H., Chem. Mater. 2005, 17, 13, 3492-3498.

26. Shibata, T.; Takanashi, G.; Nakamura, T.; Fukuda, K.; Ebina, Y.; Sasaki, T., Energy Environ. Sci. 2011, 4, 2, 535-542.

27. Ko, J.; Kim, I.; Hwang, S; Jung, H., J Nanosci. Nanotechnol. 2011, 11, 2, 1726.

28. Xu, B.-H.; Lin, B.-Z.; Wang, Q.-Q.; Pian, X.-T.; Zhang, O.; Fu, L.-M., Microporous Mesoporous Mater. 2012, 147, 1, 7985.

29. Lin, B.; He, L.; Zhu, B.; Chen, Y.; Gao, B., Cata. Commun. 2012, 29, 0, 166-169.

30. Lin, B.-Z.; Li, X.-L.; Xu, B.-H.; Chen, Y.-L.; Gao, B.-F.; Fan, X.-R., MicroporousMesoporousMater. 2012, 155, 0, 16-23.

31. Yanagisava, M.; Uchida, S.; Fujishiro, Y.; Sato, T., J. Mater. Chem. 1998, 8, 12, 2835-2838.

32. Liu, G.; Wang, L.; Yang, H. G.; Cheng, H.-M.; Lu, G. Q., J Mater. Chem. 2010, 20, 5, 831-843.

33. Akatsuka, K.; Takanashi, G.; Ebina, Y:; Haga, M.-a; Sasaki, T., J Phys Chem. C2012, 116, 23, 12426-12433.

34. Osada, M.; Sasaki, T., ECSTrans 2013, 50, 6, 111-116.

35. Sasaki, T.; Watanabe, M.; Hashizume, H.; Yamada, H.; Nakazawa, H., J. Am. Chem. Soc. 1996, 118, 35, 8329-8335.

36. Sasaki, T.; Watanabe, M., J Am. Chem. Soc. 1998, 120, 19, 4682-4689.

37. Paek, S. M.; Jung, H.; Lee, Y. J.; Park, M.; Hwang, S. J.; Choy, J. H., Chem. Mater. 2006, 18, 5, 1134-1140.

38. Kim, T. W.; Ha, H. W.; Paek, M. J.; Hyun, S. H.; Baek, I. H.; Choy, J. H.; Hwang, S. J., J. Phys Chem. C 2008, 112, 38, 14853-14862

39. Kim, T. W.; Hwang, S. J.; Jhung, S. H.; Chang, J. S; Park, H.; Choi, W.; Choy, J. H., Adv. Mater. 2008, 20, 3, 539-542.

40. Choy, J. H.; Lee, H. C.; Jung, H.; Kim, H.; Boo, H., Chemistry of Materials2002, 14, 6, 2486-2491.

41. Qiu, Y. C.; Chen, W.; Yang, S. H., J Mater. Chem. 2010, 20, 5, 1001-1006.

42. Sasaki, T.; Ebina, Y.; Kitami, Y.; Watanabe, M.; Oikawa, T., J Phys. Chem. B2001, 105, 26, 6116-6121.

43. Liu, G.; Wang, L. Z.; Sun, C. H.; Chen, Z. G.; Yan, X. X.; Cheng, L. N.; Cheng, H. M.; Lu, G. Q., Chem. Commun. 2009, 0, 11, 1383-1385.

44. Yu, H.; Zhang, S. Q.; Zhao, H. J.; Will, G.; Liu, P., Electrochim. Acta2009, 54, 4, 1319-1324. 
45. Mills, A.; Elliott, N.; Hill, G.; Fallis, D.; Durrant, J. R.;

Willis, R. L., Photochem. Photobiol. Sci. 2003, 2, 5, 591-596.

46. Ito, S; Murakami, T. N.; Comte, P.; Liska, P.; Grätzel, C.; Nazeeruddin, M. K.; Grätzel, M., Thin Solid Films2008, 516, 14, 4613-4619.

47. Wang, L. Z.; Sakai, N.; Ebina, Y.; Takada, K.; Sasaki, T., Chem. Mater. 2005, 17, 6, 1352-1357.

48. Wang, L. Z.; Omomo, Y.; Sakai, N.; Fukuda, K.; Nakai, I.; Ebina, Y.; Takada, K.; Watanabe, M.; Sasaki, T., Chem. Mater. 2003, 15, 15, 2873-2878.

49. Grätzel, M., J Photochem. Photobiol., A 2004, 164, 1-3,

3-14.

50. Harms, H. A.; Tetreault, N.; Gusak, V.; Kasemo, B.; Gratzel, M., Phys Chem. Chem. Phys 2012, 14, 25, 9037-9040.

51. Zhang, H.; Han, Y.; Liu, X.; Liu, P.; Yu, H.; Zhang, S; Yao, X.; Zhao, H., Chem. Commun. 2010, 46, 44, 8395-8397.

52. Yella, A.; Lee, H.-W.; Tsao, H. N.; Yi, C.; Chandiran, A. K.; Nazeeruddin, M. K.; Diau, E. W.-G.; Yeh, C.-Y.; Zakeeruddin, S. M.; Grätzel, M., Science2011, 334, 6056, 629-634.

53. Choy, J.-H.; Lee, H.-C.; Jung, H.; Hwang, S-J, J. Mater. Chem. 2001, 11, 9, 2232-2234.

54. Gunjakar, J. L.; Kim, I. Y.; Lee, J. M.; Lee, N.-S; Hwang, S.J., Energy Environ. Sci. 2013, 6, 3, 1008-1017.

55. Tan, B.; Wu, Y. Y., J Phys. Chem. B 2006, 110, 32, $15932-15938$.

56. Zhang, Q. F.; Dandeneau, C. S; Zhou, X. Y.; Cao, G. Z., Adv. Mater. 2009, 21, 41, 4087-4108.

57. Pang, S; Xie, T. F.; Zhang, Y.; Wei, X.; Yang, M.; Wang, D. J.; Du, Z. L., J Phys. Chem. C2007, 111, 49, 18417-18422.

58. Du, A. J.; Ng, Y. H.; Bell, N. J.; Zhu, Z. H.; Amal, R.; Smith, S. C., J Phys. Chem. Lett. 2011, 2, 8, 894-899.

59. Ito, S; Liska, P.; Comte, P.; Charvet, R.; Pechy, P.; Bach, U.; Schmidt-Mende, L.; Zakeeruddin, S. M.; Kay, A.; Nazeeruddin, M. K.; Gratzel, M., Chem. Commun. 2005, 34, 4351-4353.

60. Huang, S. Y.; Schlichthorl, G.; Nozik, A. J; Gratzel, M.; Frank, A. J., J. Phys. Chem. B1997, 101, 14, 2576-2582.

61. Gregg, B. A.; Pichot, F.; Ferrere, S.; Fields, C. L., J. Phys. Chem. B2001, 105, 7, 1422-1429.

62. Zaban, A.; Greenshtein, M.; Bisquert, J., ChemPhysChem2003, 4, 8, 859-864.

63. Kuang, D.; Uchida, S; Humphry-Baker, R.; Zakeeruddin, S. M.; Grätzel, M., Angew. Chem. Int. Ed. 2008, 47, 10, 1923-1927.

$64 . \quad$ Liao, J.-Y.; Lin, H.-P.; Chen, H.-Y.; Kuang, D.-B.; Su, C.Y., J Mater. Chem. 2012, 22, 4, 1627-1633. 


\section{Table of Contents}

PorousTitaniaNanoshee/ NanoparticleHybridsasPhotoanodesfor Dye-sensitized Solar Cells

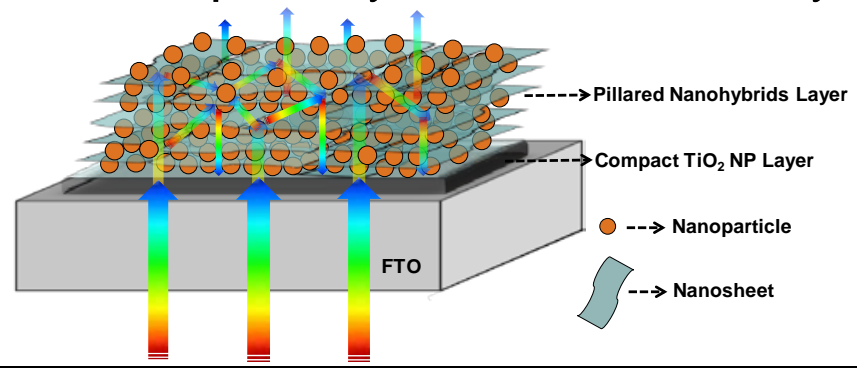




\title{
Supporting Information
}

\section{Porous Titania Nanosheet/Nanoparticle Hybrids as Photoanodes for Dye-sensitized Solar Cells}

\author{
Yang Bai, ${ }^{a}$ Zheng Xing, ${ }^{a}$ Hua Yu, ${ }^{a}$ Zhen Li, ${ }^{b}$ Rose Amal, ${ }^{a}$ and Lianzhou Wang ${ }^{* a}$
}

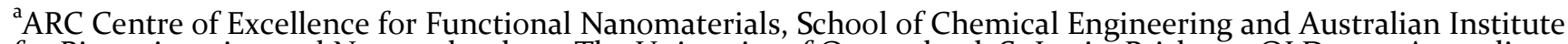
for Bioengineering and Nanotechnology, The University of Queensland, St Lucia, Brisbane, QLD 4072 Australia.

${ }^{\mathrm{b}}$ Institute of Superconducting and Elctronic Materials, Australian Institute of Innovative Materials, The University of Wollongong, Squires Way, Northwollongong, NSW 2500, Australia.

${ }^{\mathrm{c}}$ ARC Centre of Excellence for Functional Nanomaterials, School of Chemical Engineering, The University of New South Wales, Sydney, NSW, 2052, Australia.

*Corresponding Author. Email Address: l.wang@uq.edu.au
\end{abstract}
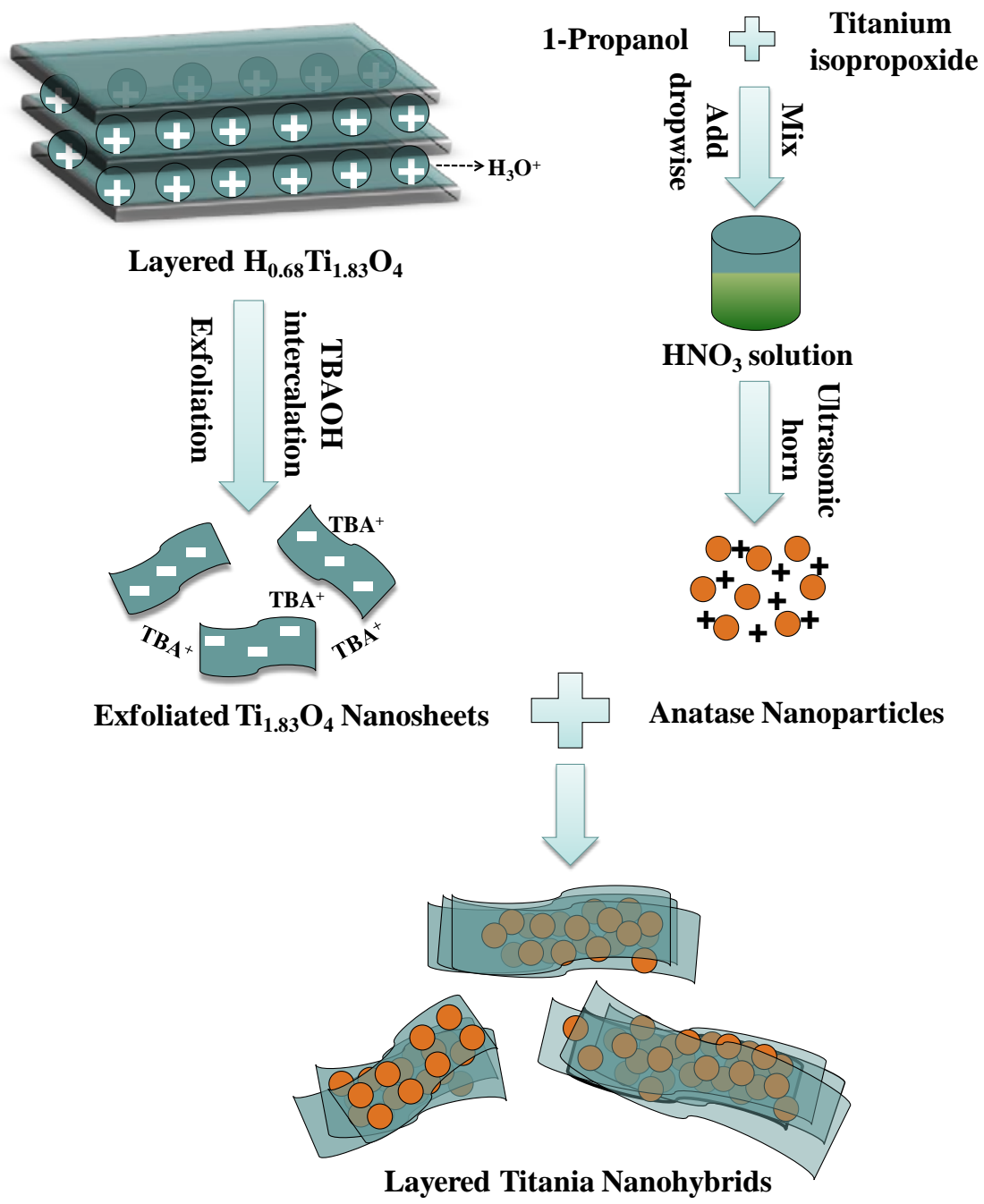

S-Figure 1 Schematic diagram for an exfoliation-hybridization route to prepare layered titania NHs 

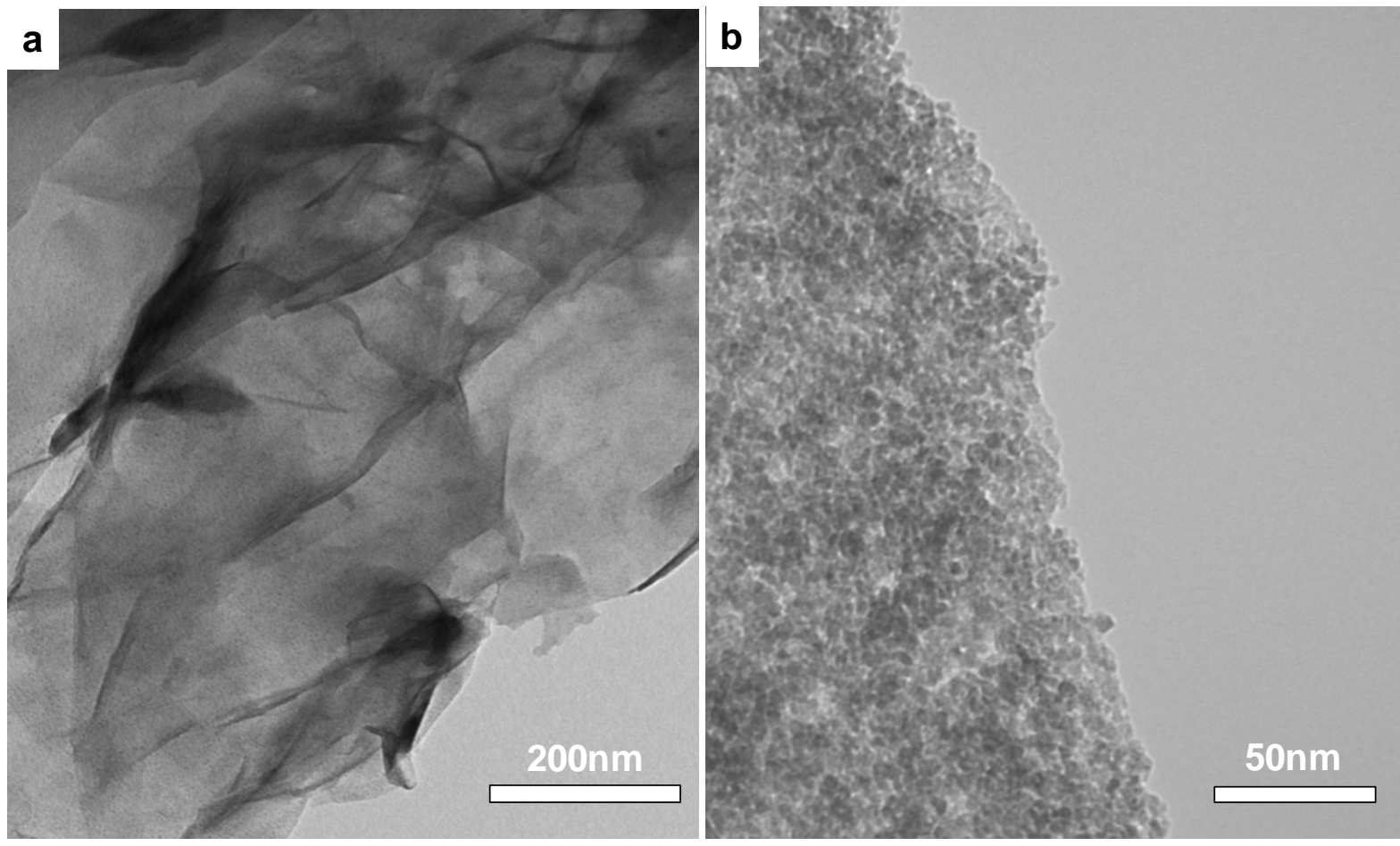

S-Figure 2 TEM of a) exfoliated $\mathrm{Ti}_{0.91} \mathrm{O}_{2}$ nanosheets, and b) anatase nanoparticle prepared from hydrolysis of titanium isopropoxide.

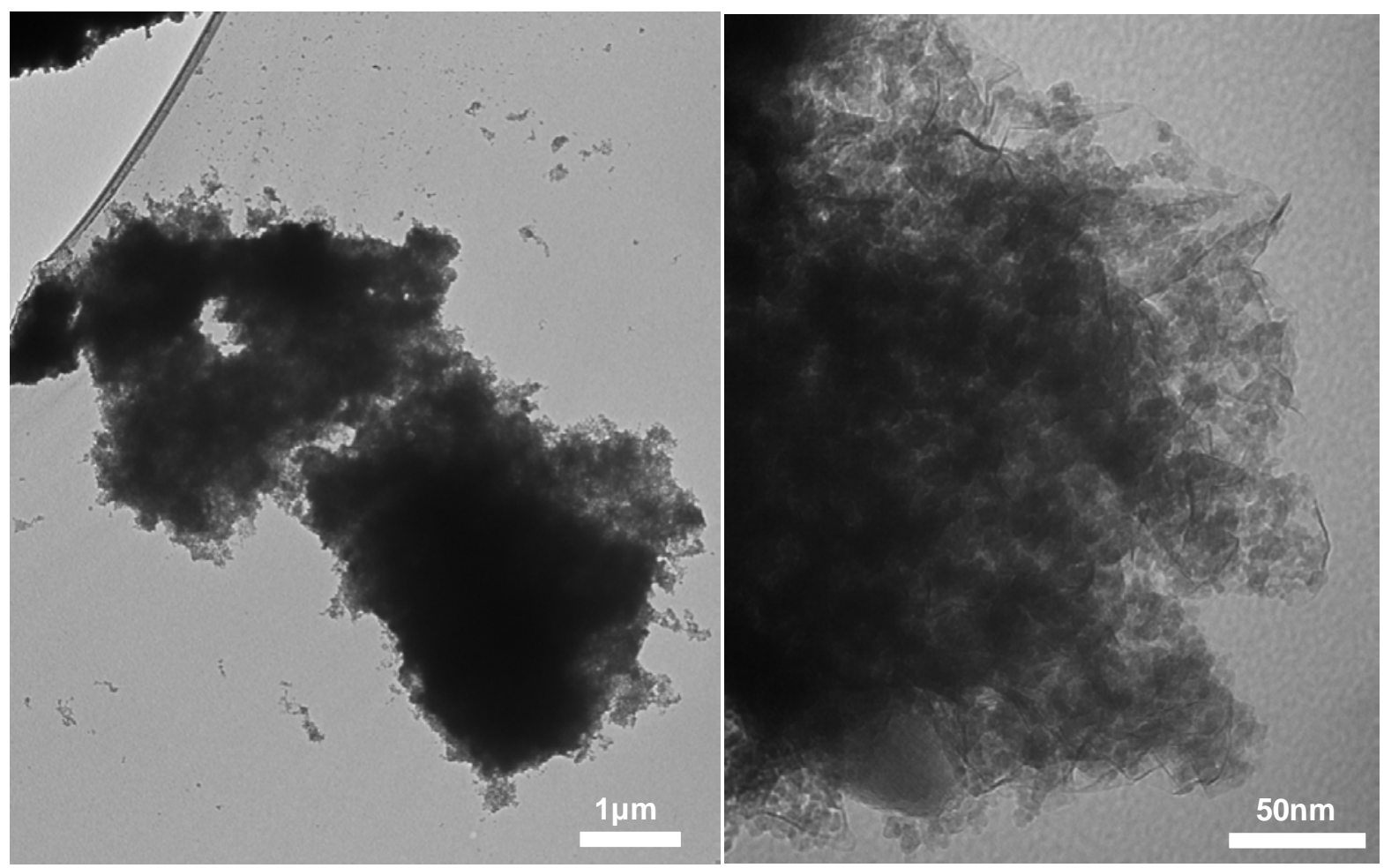

S-Figure 3 TEM of restacked nanohybrids. 


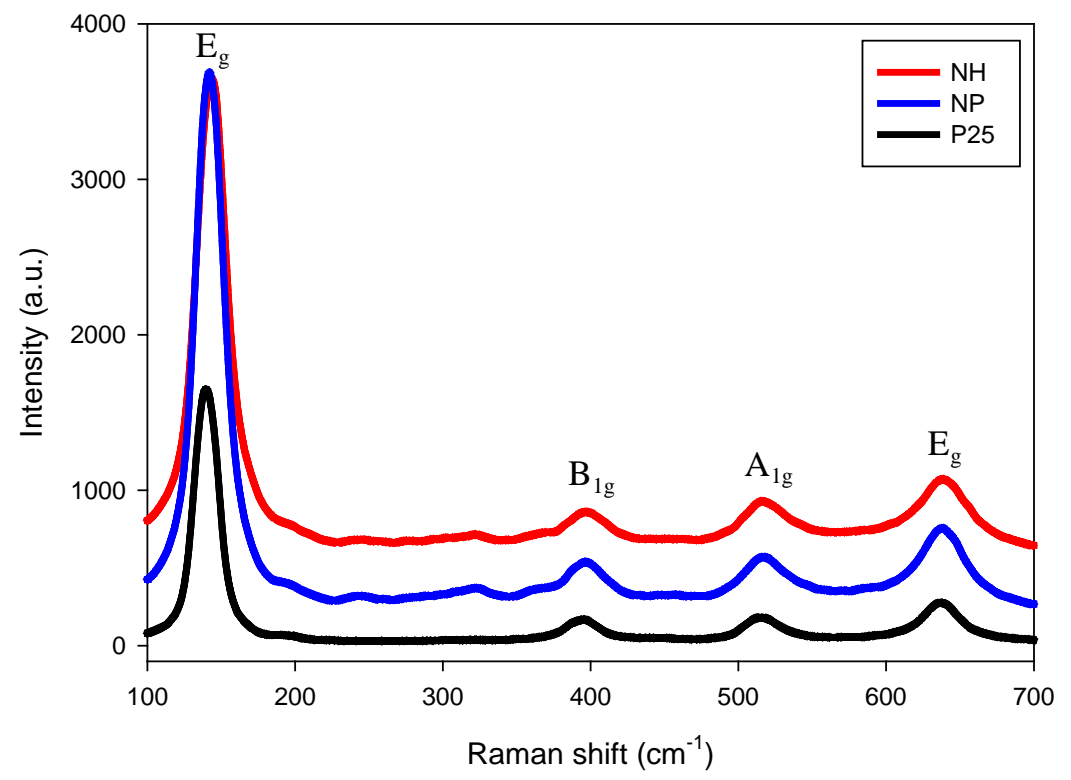

S-Figure 4 Raman spectra of $\mathrm{P}_{25}$, NP and NH films.

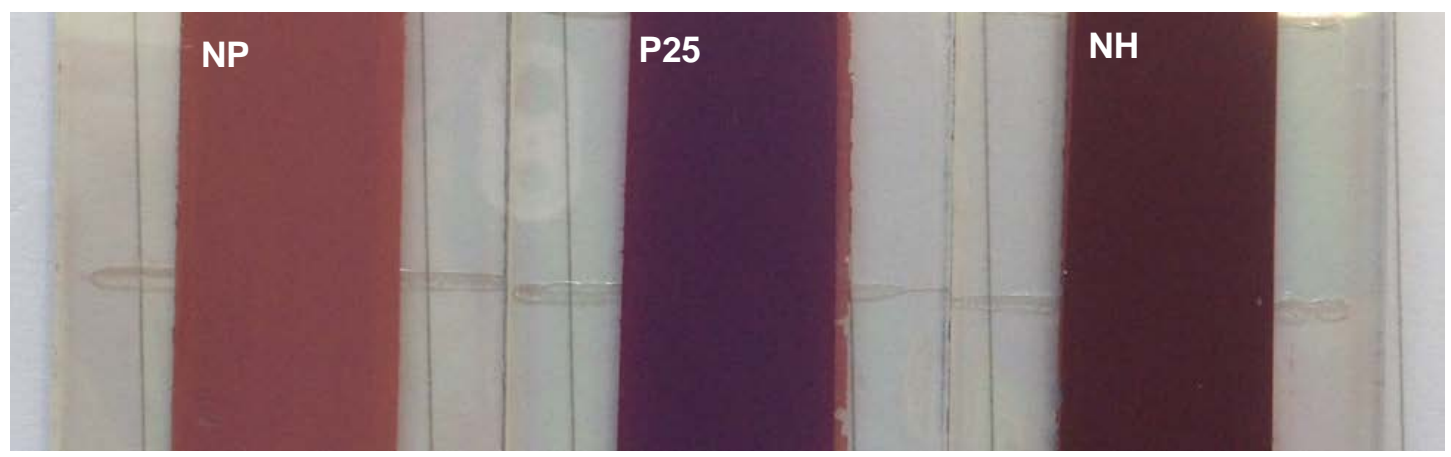

S-Figure 5 Corresponding photos of NP, P25 and NH films after dye adsorption.

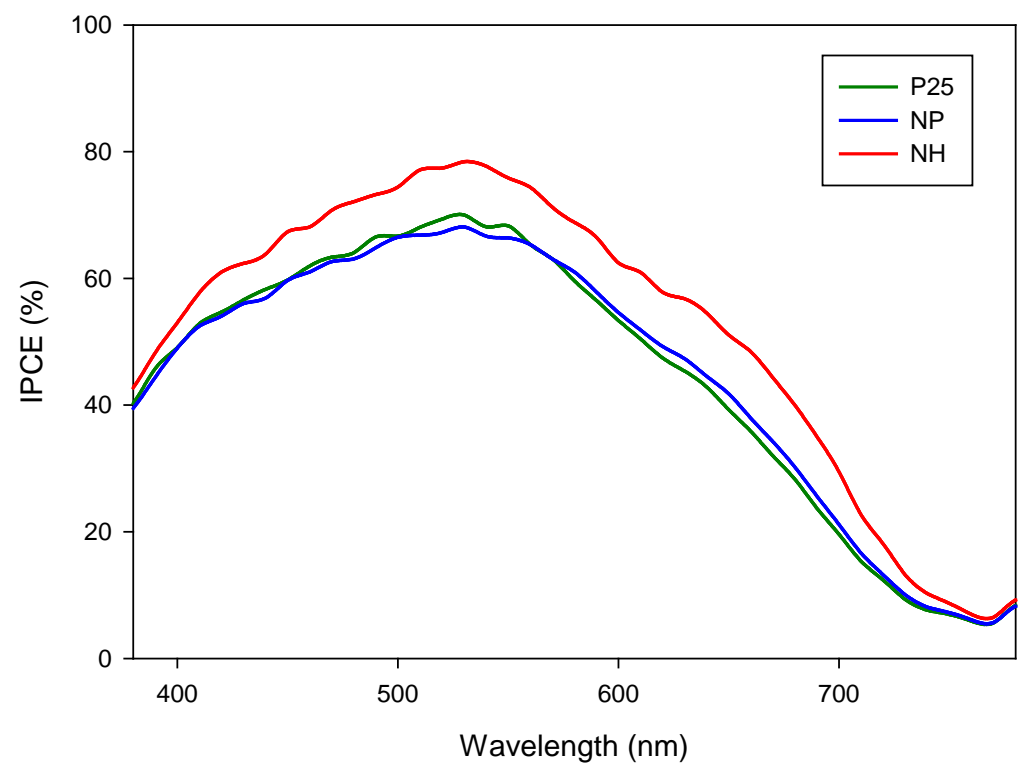

S-Figure 6 IPCE of DSSCs based on P25, NP and NH photoanodes. 

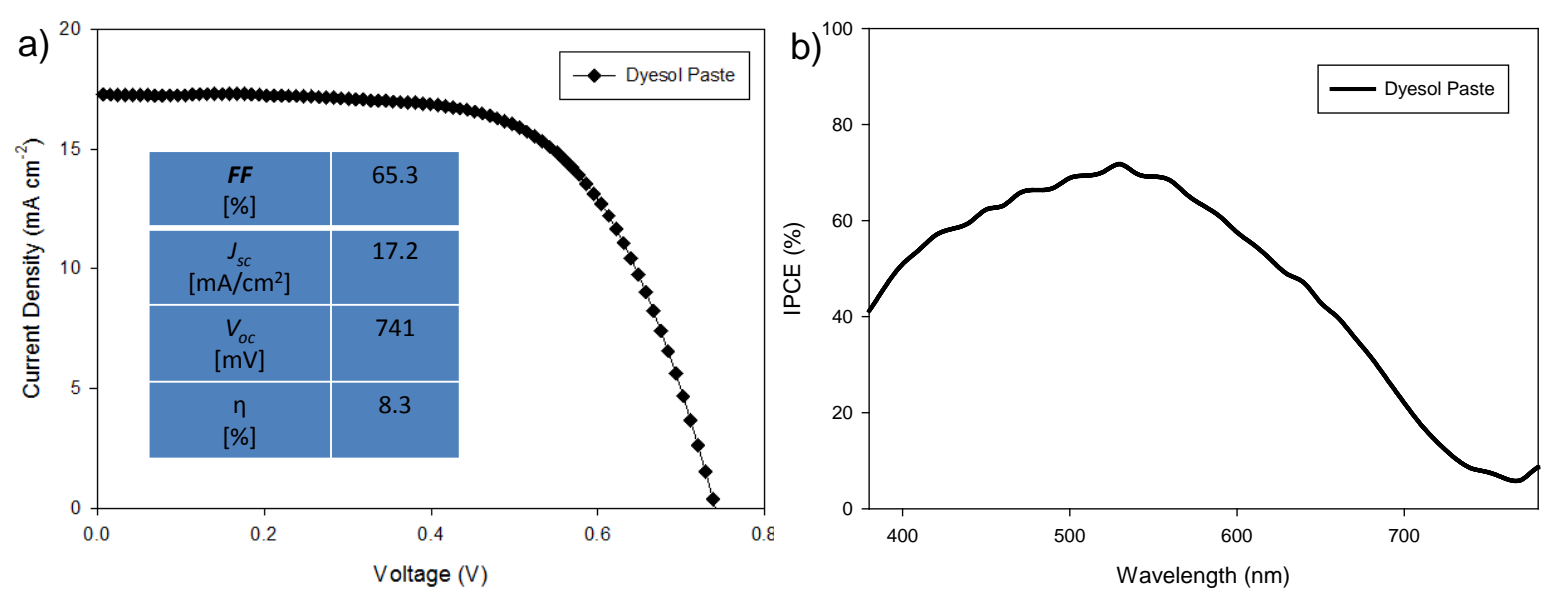

S-Figure 7 a) $J$ - $V$ curves and b) IPCE of DSSCs based on photoanodes composed of commercial Dyesol paste (18NR-T Transparent Titania Paste). 